\title{
"You Feel The Threat From Asia". Onshore Experiences of IT Offshoring To India
}

\section{Martha Blomqvist'}

Associate Professor, Senior Researcher, Centre for Gender Research, Uppsala University, Sweden

\section{Helen Peterson}

Associate Professor, Senior Lecturer, Department of Sociology and Work Science, University of Gothenburg, Sweden

\section{Sunrita Dhar-Bhattacharjee}

Senior Lecturer, Lord Ashcroft International Business School, Anglia Ruskin University, UK

\begin{abstract}
This article investigates the experiences of employees and managers in Swedish companies that offshore IT services to India, focusing on how implementation of offshoring is changing the work organization and working conditions for software developers onsite. Our analysis highlights the fact that the working conditions have been significantly redesigned in several different ways because of offshoring, most obviously due to the need for knowledge transfer between the onshore and the offshore working sites. The study illustrates how employees and managers onsite utilized different strategies for knowledge transfer and how these strategies were more or less successful, sometimes due to resistance from employees. The article concludes that, although offshoring contributed to a separation of conception from execution in these companies, there were few signs of routinization of daily work tasks for onsite employees. Instead, it was the routinized and noncore tasks that were offshored while project management tasks were taken over by onsite staff, which meant that they ended up in a superior position vis-à-vis their Indian colleagues as new global hierarchies were created. Power relations at work, both within firms and between firms, are thus brought to light.
\end{abstract}

\section{KEY WORDS}

India / Knowledge transfer / Labor processes / Offshoring / Onsite employees / Organizational change / Power relations / Resistance / Software development / Sweden

\section{DOI}

10.19154/njwls.v5i4.4843

\section{Introduction}

ffshoring is an abbreviation for offshore outsourcing and usually refers to how companies relocate jobs or activities abroad, typically to low-wage countries (Hovlin 2006; Mattila and Strandell 2006). The consequences of offshoring for the economy and for global labor markets have been described as far-reaching and widespread (King 2005). Alan Blinder (2006) depicts the situation in dramatic terms in discussing offshoring of services as the third industrial revolution. The first industrial revolution involved

\footnotetext{
${ }^{1}$ E-mail: martha.blomqvist@gender.uu.se
} 
the transfer of jobs from agriculture to manufacturing, and the second from manufacturing to services. According to Blinder, we are now in the early stages of a third industrial revolution - the information age-where services have become tradable. Just like previous industrial revolutions, this one will require vast adjustments in the developed countries. Blinder does not foresee massive unemployment; rather, a great transition and new geographical division of labor, and therefore finds it of the outmost importance that the nations losing jobs to, for example, India, should make adjustments and prepare themselves for what is about to happen. He writes: 'An effective safety net would ease the pain and, by so doing, speed up the adjustment' (Blinder 2006, p. 7).

Global software outsourcing, i.e., the outsourcing of software production from developed countries to emerging economies, is a relatively new form of offshoring (Gannon et al. 2014; St. John et al. 2014) and part of the 'sudden increase' in the offshoring of knowledge services that has evolved since the late 1980s, made possible, as well as driven by, rapid technological advances (Metters and Verma 2008, p. 141).

India is the global choice for offshoring of IT services, with a market share of $59 \%$ (Ravishankar et al. 2013; United Nations 2012). Its success is the outcome of a national investment in telecom and computing infrastructure, built up over many years, with the active involvement of the Indian government (Tessler et al. 2003). When the Indian markets were opened up to world trade in the early 1990s, investment in the software industry was encouraged (Metters and Verma 2008). The government also invested heavily in education, and foreign investment in software meant that the numerous graduates in engineering and computing could find employment without going abroad (Dossani and Kenney 2007). There are thus 'large pools of English-speaking engineering graduates' (Ravishankar et al. 2013, p. 387) available in India. Although the high-tech sector accounts for only $0.2 \%$ of employment, software and IT services make up an important part of the Indian economy and of the image of the 'new' India (Friedman 2005; Radhakrishnan 2007).

One reason for moving jobs offshore is a shortage of labor (Lewin et al. 2009), but the primary reason for most companies is to save money (Bhalla et al. 2008; Marklund 2007; Massini et al. 2010) and, in this context, Indian software engineering wages have proved highly competitive compared to those in the West (Luftman and Kempaiah 2007).

Global software offshoring from countries in the West to countries in Asia also benefits the offshoring companies as they can exploit 'follow-the-sun' development to improve time-to-market (Rau 2004).

English-speaking countries were the first to offshore IT jobs. In the USA, offshoring of goods as well as services has provoked political discussion, fueled by fear of job losses, which was especially heated during the 2004 election year (King 2005; Metters and Verma 2008). In 2009, during his first weeks in office, Barack Obama made it clear that he intended to discourage outsourcing in general (Srivastava 2009), and in 2012 he predicted tax reforms to that effect (Obama 2012). Whether changes in tax policy will reduce the expansion of IT jobs to offshore locations remains to be seen, however. The wage gap between India and the USA, the possibility of finding sufficient numbers of technical workers at short notice and India's young population may be more significant incentives for relocating jobs than tax policy (Lacity et al. 2009; Roza et al. 2011).

An estimate by Forrest Research (2004) (in Hovlin 2006) mentions a total of 20,000 Swedish jobs to be moved offshore by 2025 . Of these, 5,400 are IT jobs. Recent figures 
suggest that this may be an underestimate. In the last four years alone, the four largest US-owned IT companies in Sweden have dismissed almost 1,000 employees in Sweden, while Indian consultancies are increasing their share of the Swedish market (Computer Sweden 2013b). A Finnish-Swedish IT company reported a radical increase of competition from India during 2013 and therefore planned to dismiss almost 800 employees (Computer Sweden 2013a). From an international perspective, these figures may seem quite insignificant, but Sweden is a small country and the private sector employs only 77,000 computer systems designers and programmers (Statistics Sweden's category for software developers) (Statistics Sweden 2014).

This article investigates the experiences of employees in Swedish companies that offshore IT services to India. Sweden has not (yet) had such a noticeable public debate on the effects of offshoring as in the USA, and layoffs in the IT sector seldom reach the headlines in the daily newspapers or television (Hovlin 2006). Statistics show that the offshoring activities in Sweden are slightly higher than the average in other European countries (Werner 2009), but it can be hard to estimate the real numbers of IT jobs relocated offshore since offshoring is a multifaceted phenomenon (Mattila and Strandell 2006). Some jobs are offshored from IT firms, others from IT departments in companies in other sectors, while some go directly to India, instead of to a Swedish IT firm, sometimes as a result of expansion. In the long run these latter instances might result in layoffs in domestic IT firms since they are losing potential customers (Hovlin 2006).

Although relatively few employees in the Swedish IT industry are directly affected by offshoring (Hovlin 2006), the consequences for those working in companies that decide to offshore jobs can be expected to be significant. This paper looks into how implementation of offshoring is changing the work organization and working conditions for software developers in Sweden. To do so we analyze interviews with managers and employees in two Swedish IT firms that have offshored some of their software development to India. More specifically, the research question we deal with in this paper is: How does offshoring transform labor processes in onshore sites, and what are the consequences for the working conditions and working environments of software developers in these workplaces?

Internationally, the topic of outsourcing and offshoring has started to attract academic interest (Lacity et al. 2009), although the research literature on the organization and management of offshore outsourcing of IT services is still limited (Gannon et al. 2014). Apart from a couple of reports (Hovlin 2006; Marklund 2007; Mattila and Strandell 2006) and working papers (Ekholm and Hakkala 2005; Rognes 2008), research on offshoring has been almost nonexistent in Sweden (one recent exception is Westermark 2013). The majority of the available texts adopt a macro-level perspective on offshoring as a phenomenon, presenting statistics on the extent of offshoring on the Swedish labor market and the current trends, the reasons for companies to offshore, and the challenges of offshoring for the industry, policymakers, and companies. These existing studies provide us with important information and knowledge about offshoring in Swedish companies, but more research is needed to understand the radical transformation of working conditions that offshoring entails for employees in those Swedish companies that offshore jobs abroad. To our knowledge, no previous studies have looked into how offshoring of IT jobs affects working conditions for employees in Sweden. This article therefore aims to contribute to a 'more complete understanding of offshoring' by 'bringing employees into the conversation,' as expressed by Woodard and Sherman (2015) 
(although their study focuses on employees in the destination country who are performing customer service and telemarketing roles).

The article is structured into five sections. Following this introduction, we introduce previous research on offshoring, organizational changes, and resistance. We also offer a brief account of labor process theories, which we suggest can be used to understand how offshoring changes working conditions for employees. The subsequent section deals with the methodological considerations and presents the empirical data. After that, we present the empirical findings and the analysis. The article ends with a concluding discussion.

\section{Previous research and theoretical framework}

\section{Labor process theory and offshoring}

The analysis in this article of how offshoring influences working conditions for software developers in onshore organizations is inspired by the specific strand of critical working life research called labor process theory (cf. McCabe 2014). Labor process theory follows in the footsteps of Harry Braverman's (1998 [1974]) analysis, published in 1974, of the labor process within a capitalistic society. The core in this analysis is the critique of the degrading of work and deskilling of employees that is the result of the three management principles dominating scientific management, or Taylorism. The first of these principles concerns: '.. gathering together all of the traditional knowledge which in the past has been possessed by the workmen and then of classifying, tabulating, and reducing this knowledge to rules, laws, and formulae.' Braverman calls this first principle the 'dissociation of the labour process from the skills of the workers. The labour process is to be rendered independent of craft tradition, and the workers' knowledge' (Braverman 1998 [1974], p. $77 \mathrm{ff}$ ). The second principle reads: 'All possible brain work should be removed from the shop and centered in the planning or laying-out department [...].' Braverman (1998 [1974], p. 79) calls this the 'separation of conception from execution,' meaning that knowledge is concentrated in the hands of management. The third principle is the 'use of this monopoly over knowledge to control each step of the labour process and its mode of execution' (ibid, p. 82). Together, these principles state that conceptual work is taken over by management, leaving workers with only execution tasks, all of which are planned and controlled by management. The result is the deskilling of the labor force and the routinization of work.

Software developers are definitely not among whom we would expect to encounter deskilling of their jobs. On the contrary, they are among those predicted to become the future aristocrats of the labor market (Castells 1996), being at the core of the rising creative class (Florida 2002) and referred to as 'gold-collar professionals' (Barrett 2005, p. 4). Nevertheless, some researchers point at neo-Taylorist management techniques being implemented also in the software industry. Upadhya (2009) studied the effects of outsourcing on the labor process and on labor relations, and the consequences for knowledge workers in India. Her analysis illustrates how Indian software companies implemented management strategies to maximize software labor productivity, resembling a top-down Taylorist system of management control over the labor process, the highly skilled knowledge workers, and the workers' knowledge. Hakken (2000) (in Upadhya 2009) uses the concept 'cyberspace labour process' to refer to knowledge-intensive

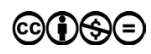


organizations that try to control the knowledge of employees. In these companies the labor process emphasizes communication, collaboration, teamwork, and knowledge sharing through building strong social networks.

Previous research illustrates how essential knowledge transfer is for the possibilities to offshore. Knowledge transfer can be managed in a variety of ways, but as a rule offshoring starts with work being documented and standardized (Rognes 2008). Documentation and standardization processes are what local trade unions are advised to look out for as two of the signs that a company is considering offshoring (Bruyn and Ramioul 2006; Unionen 2008). This kind of knowledge transfer was also a focal theme in scientific management, applied within the manufacturing industries in the early 20th century, although, at that time, the individual workers' knowledge was documented and transferred to new workers and transformed into tools and processes, controlled at the supervisory level. Management thereby became more independent of individual workers and the highly skilled workers lost their previous status.

Rognes (2008) studied offshoring from Sweden to call centers in the Philippines, and stresses that knowledge transfer between the two sites must encompass not just explicit and formal knowledge, but also tacit knowledge and situated knowledge. He emphasizes the importance of standardization of services as being key to cost-efficient offshoring, and suggests that future research should focus on the professional roles of the employees in the onshore sites. If standardized and routine tasks are outsourced, the complexity of work for the employees can increase and labor processes can become more complex and challenging.

Among the proponents of the routinization or deskilling thesis we also find Beirne et al. (1998), who state that the process of software development is moving away from individualized craft-like production toward a more routinized factory-like production process. Aneesh (2001) and Barrett (2001) declare in a similar vein that the development of structured programming and object-oriented languages that allow for modular programming, and the use of software engineering tools, have led to the emergence of 'software factories' or 'assembly lines' for software development (cf. also Upadhya and Vasavi 2008). Rejecting the deskilling hypothesis are Andrews et al. (2005) and Ilavarasan (2008), who state that conception ('conception of idea for the software and preliminary analysis' and 'designing') and execution (coding, testing, and maintenance) cannot be completely separated in software development.

\section{Offshoring challenges and strategies}

Spatial aspects can be seen as central to understanding the challenges in global software offshoring. Recent debates within economic geography have highlighted how space, proximity, and local embeddedness matter for businesses and the process of knowledge formation, learning, and innovation (Amin and Cohendet 2005; Strengers 2014). Different dimensions of distance have often been perceived as inhibiting innovation and growth since they can prevent an efficient flow of information between firm and market (Metters and Verma 2008; Ramarapu et al. 1997). The development of trust in business relationships has also been described as requiring spatial proximity, at least initially (Grote and Täube 2006). Cross-cultural communication has been described as a tangible challenge for management and employees, both onsite and offshore (Ainamo et al. 2010; 
King 2008; Nicholson and Sahay 2004; Sahay et al. 2007). Communication in a multinational work environment involves not only different languages and cultures but also different time zones, which can both be beneficial, since they allow for increased flexibility and for 24/7 project work, but which can also exacerbate the communication problems and impede effective collaboration (Dou and Sarkis 2010; Markov et al. 2011).

The key factors for successful offshoring concern communication and two-way exchanges of information, trust, and honesty in negotiations, shared values and partnership, and collaboration to attain mutually beneficial goals (St. John et al. 2014). There are many examples of spatial strategies to overcome the business challenges related to a lack of spatial proximity for geographically dispersed teams: traveling to facilitate regular face-to-face meetings; teleconferences; elaborate communications networks; and virtual communities (Amin and Cohendet 2005; Markov et al. 2011; Strengers 2014). So-called organizational or professional proximity, created through shared routines, experiences, language, ideals, methods, and practices, can also partially compensate for a lack of geographical proximity (Grote and Täube 2006; Westermark 2013).

Carmel and Tjia (2005) identified five typical problems when people try to collaborate across distances in offshored relationships: communication breakdown, coordination breakdown, (managerial) control breakdown, cohesion barriers, and culture clashes. Tambe and Hitt (2010) suggest that offshoring leads to a shift in the demands on IT workers onsite toward the need for the 'softer' skills of an interpersonal and managerial character that promote teamwork, such as communication and presentation skills.

\section{Organizational change, resistance, and power}

The introduction of offshoring in a workplace can be defined as a strategic and transformational type of organizational change that alters the general working framework and the boundaries of the firm (Vosselman and van der Meer-Kooistra 2006). This type of organizational change has been described as presenting employees with 'a chaotic organizational reality' (Vaara and Tienari 2011, p. 372). Individual employees' responses to such fundamental organizational change can be expected to involve resistance and opposition (Pardo de Val and Martínez Fuentes 2003).

In an organizational setting characterized by processes of change initiated by top management, employee resistance can be either active or passive, overt or covert, and be expressed in a wide variety of ways: not actively supporting change initiatives, doing the minimum required, using counter-arguments, non-cooperation between professional groups, slowing down work, voicing of concerns about the future, and ultimately exiting the organization (Erwin and Garman 2010; Ford et al. 2008; Pieterse et al. 2012; Thomas et al. 2011).

There are several influences on employees' responses to organizational change, which can either increase or decrease resistance: individual personality (dispositional inclination, personal resilience, risk tolerance); change process factors (such as consistency of management actions, participation, communication); and management interaction styles (producing confidence, trust, skepticism, cynicism, frustration, or enthusiasm in employees) (Erwin and Garman 2010; Pardo de Val and Martínez Fuentes 2003).

Resistance to change is closely linked to organizational power and unequal power relations (Pieterse et al. 2012). This article addresses issues of power by investigating 
how power relations both within and between firms intersect to influence employees' experiences of the labor processes after the introduction of offshoring in their companies.

Investigating power relations within firms involves, for example, taking into consideration the relationships between management and employees when it comes to employee resistance and consent in respect to organizational changes (McCabe 2014). Boes and Kämpf (2010) explore how the work situation (and interest orientations) of highly qualified employees in software development in Germany has changed as a result of, first, the crisis of the new economy and then further accentuated by offshoring strategies. Their findings concern an economization of corporate cultures, a loss of a culture of trust between employees and management, and a new experience of insecurity.

Asymmetrical power relations between onshore and offshore firms, or between onshore headquarters and offshore subsidiaries, are inherent to the global software offshoring phenomenon and contribute to the so-called international division of labor (Arora et al. 2001). Outsourcing companies occupy a position of power since they control the primary domain knowledge, define the standards of work, and how they should be enforced in practice (Sahay et al. 2007). It is often noncore/noncritical and routinized tasks, the non-innovative work, testing and online technical support that is offshored to countries like India (Luftman and Kempaiah 2007; Ramarapu et al. 1997). As knowledge is gradually transferred to the contracting company, however, there can be a degree of reconfiguring of the power differential between onshore and offshore companies (Sahay et al. 2007).

In the broader perspective of global software outsourcing, asymmetries of power relationships influence the choice of offshoring destination that often follows historical colonial patterns since English is a key determinant and 'cultural proximity' is believed to facilitate greater success (Metters and Verma 2008; Mir and Mir 2009).

It is therefore important to understand employees' resistance in an organizational setting characterized by cross-cultural encounters and power-related asymmetries from a perspective of postcolonial power relations, since such resistance can take the form of stereotypes, cross-national comparisons, and the promotion of national interest (Ravishankar et al. 2013; Vaara and Tienari 2011). Van Marrewijk (2010) studied the offshoring of IT services from the Netherlands to India in four multinational corporations, and he illustrates how Dutch front offices and Indian back offices are involved in struggles over project control, client contact, and high-end jobs. The Dutch fear of losing power over project management control to the Indian back offices even resulted in the Dutch welcoming the failure of global projects, as such failures strengthened their position. Van Marrewijk's results show that the employees constructed cultural differences and used them as strategic resources and arguments to gain control over high-end IT jobs.

In their study, Cohen and El-Sawad (2007) focus on employees' experiences of offshoring in a financial services company with offices in the UK and India. Their analyses and conclusions resemble van Marrewijk's (2010) since they examine how employees in both settings account for cultural differences in order to position themselves in relation to one another. Cohen and El-Sawad, similarly to van Marrewijk (2010), also identify language issues, work ethics, and notions of competence as central in these accounts. 


\section{Methodology}

Within the framework of our research project, semi-structured interviews in four companies were conducted in Sweden and India. Interviewees were managers at different levels and employees, mostly software developers. Software development includes specification, analysis, design, implementation, testing, and maintenance (United Nations 2012). Employees were asked questions about their background, recruitment, career, work tasks, positive and negative aspects of offshoring, communication with Indians/ Swedes, cultural differences, salaries, working hours, work-life balance, working conditions, and work climate. Managers were asked questions about their background, work tasks, gender division among their employees, the introduction of offshoring, recruitment to offshoring teams, challenges due to offshoring, and cultural differences. Interviews lasted on average around one hour. The interviews were recorded and transcribed. Two of the four companies were small start-ups, while two were big multinationals.

The management in the companies allowed access to workplaces and interviewees. Many interviewees were quite outspoken about their offshoring experiences, including about the negative aspects, but we assume that some of them would have felt freer to raise criticisms had the setting and circumstances of the interviews been different. Information was also obtained from meetings in the companies. We were quite generously invited to attend meetings at a team level as well as at management level in the two multinationals in Sweden.

This article addresses the question of how employees experienced changes in working conditions due to offshoring. Working conditions for Indian employees working at the offshore facilities have not changed due to offshoring, since the companies were involved in offshoring already when they were recruited. The same applies to Swedish employees in the start-ups. This article does not, therefore, deal with the experiences of either employees in India or employees in start-ups. For Swedes employed by the multinationals, however, we can expect to see changes in working conditions as a result of the implementation of offshoring. This article, therefore, builds on information from interviews and meetings in the Swedish offices of these two companies. The decision to focus on interviews with Swedish onshore employees was based on a desire to contribute to the identified gap in the previous research literature on offshoring. Although outside the scope of this article, we also recognize the importance of researching labor processes offshore and working conditions for offshore employees. Interviews with managers and employees in India are, therefore, discussed in other papers arising from this research project.

All interviewees were promised confidentiality and anonymity, and the two companies, described below, are given pseudonyms. Careful attention to confidentiality issues also restricted our analysis of, for example, employees' stories about resistance, since some of the more controversial ones were considered as too sensitive to pass on.

Cindicom is a regular IT firm, based in another European country, and offshores to the company's offices in India. This was a decision imposed by headquarters and nothing the Swedish managers could influence. This company is thus an example of internal or captive offshoring, meaning that the company has relocated some of its services to India but continues to perform them itself, only in affiliates located outside the home country (cf. Kenney et al. 2009; Prikladnicki and Audy 2012). At an early stage of the offshoring some employees from the Indian office visited Sweden for a few weeks. The purpose of

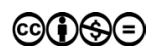


these visits was to get an understanding of how work was organized in Sweden and to build relationships with the Swedish teams. A few Swedish employees, team leaders, and project managers also visited the Indian offices, thereby building a personal relationship with Indian colleagues. Cindicom has had layoffs as a direct result of offshoring. This article draws on interviews with 18 Swedish managers and employees at Cindicom. None of the laid off employees were interviewed.

Doniman is a manufacturer of goods, with a large IT department, and is based in Sweden. Since the company does not have offices in India it offshores to an external company in India that has a long history of cooperation with Doniman, distributing its goods in India. This is, therefore, an example of external offshoring, meaning that the company has hired another firm to perform the services (cf. Gannon et al. 2014). This Indian company also sends software developers employed by them to work for some months at Doniman's offices in Sweden, thereby developing their knowledge of the company and its IT products. So far, Doniman has not laid off any employees due to offshoring; redundant employees have been offered new jobs in other parts of the company. This article draws on interviews with 12 managers and employees at Doniman.

The interviews were analyzed by coding and categorizing to discover salient issues and themes in the employees' experiences (cf. Fereday and Muir-Cochrane 2006). The authors continuously conferred with previous research to provide a framework for the analysis. Within this framework, the primary objective was to understand, interpret, and represent the subjective viewpoints of the interviewees in order to capture the qualitative richness of the data.

The analytical section that follows below is divided into four subsections based on a categorization of the primary dimensions of impact of offshoring, as experienced by the employees. These dimensions emerged as prominent themes induced from the empirical data (cf. Ryan and Bernard 2003). The four primary dimensions are organizational, operational, cultural, and economic. The organizational dimension concerns how offshoring is perceived to affect the structure of the organization, but also the skills of employees. The operational dimension involves factors about how offshoring affects the processes, practices, and methodologies used in work. The cultural dimension concerns the aspects of offshoring that have a cultural interpretation or relate to cultural aspects. The economic dimension addresses the effects of offshoring on the economic situation of the employees themselves, or of the society.

\section{Findings and analysis}

\section{Organizational dimensions}

The introduction of offshoring in the labor process more or less inevitably entailed a new organization of work and a new division of labor in the companies. Consistent with previous research (Kenney et al. 2009), our case study firms had relocated mainly routinized work and nonstrategic tasks to India. Doniman emphasized the importance of not sending strategic tasks to India, while Cindicom was less absolute about this. The difference makes sense, considering that Doniman offshored to an external company and Cindicom to its own offices in India. The result was a new division of labor in which the execution of routine tasks was distinguished and separated from more strategic tasks, 
described by interviewees at Doniman as: 'The tasks offshored are these more simple tasks, the routine tasks, that might not be that much fun to do' (Software developer, Doniman). A mid-level manager at Doniman explained the management perspective and how concern for the onsite employees influenced their offshoring strategy:

It's important to emphasize that we haven't laid off any of our employees. We are very committed to our employees' development. What are they interested in? They always want change, to develop and have challenges. And there are always things that they are not interested in. And those are the tasks that we offshore. We always try to keep the core tasks here. (Mid-level manager, Doniman)

Insofar as execution tasks were sent to India and conception tasks kept in Sweden, the change in the labor process meant that conception and execution were at least partly separated - including spatially. The execution tasks were replaced, for onsite staff, with more administrative, planning, and supervisory tasks. The software developers onsite therefore experienced a slight shift in their professional role as they took on more project management work tasks. Despite the concerns of the managers in Doniman, however, this was not always a development that the onsite employees welcomed. For software developers who have avoided a traditional career in order to pursue specialization in software development, this change may not be very attractive. A software developer shared his concerns regarding his future work tasks:

The Indians are envisaged as having certain kinds of jobs; they will do development and they will handle incidents. So we will have a number of other roles, we will be administration managers and responsible for different things. We will kind of have the main responsibility. If I would like to work with something else, it will be within a very limited area. I have to apply for other managerial roles, because in them we will still have Swedes. [...] I may not be interested in stepping up to become a manager-or I probably won't want to-but I would like to try new tasks. Then there will be no other tasks for us employees; they will be in India. (Software developer, Doniman)

When executive software development tasks are shipped offshore, there is a risk of weakening the existing technical expertise onshore, which could be interpreted as an example of the deskilling or deprofessionalization of onshore employees. On the other hand, this new division of labor also implies a kind of job enrichment when onshore employees are assigned increased responsibilities previously reserved for higher-level employees or managers. The onsite employees thus found themselves part of a professionalization of project management tasks (cf. Meil 2012).

Work was typically organized in teams in the case study companies. Some of these teams had a long history of working together for years before the offshoring processes started. The introduction of offshoring, however, meant that work became organized in more geographically dispersed teams, which increased efficiency and flexibility in that project work could become extended in time with onsite employees delivering and handing over work to their offshore colleagues in another time zone at the end of their working day. However, how to organize work together with new team members proved to be a continuous challenge for the teams onsite that needed to be constantly prepared to welcome new Indian members into the teams. 
High attrition rates are characteristic for the Indian software industry. Most of the turnover tends to be junior developers who join a competing company for higher salaries or leave for purposes of pursuing higher studies abroad (Sahay et al. 2007; Simhan 2014). Career advancement is thus the driving force behind high attrition. An Indian manager based in Sweden explained, drawing on what seems to be cultural explanations:

In India, there is a pressure on going up the ladder. People want to move up. In Sweden a lot of developers are happy doing development all their working life. This does not happen in India. If you don't move up your family or spouse will put a lot of pressure on you. (Manager, Doniman)

Attrition had severe immediate consequences for the organization of work and for the work tasks onsite, since new staff had to be trained offshore. After offshore team members had been trained successfully the process sometimes had to be repeated over and over again, which caused irritation onsite. One of the interviewees explained:

It's frustrating. [...] You explain everything and train someone. Within 3-4 months that person is gone and replaced by someone new. There are new people every year. So we have a lot of problems... We really tried in the beginning but it's no use because within a couple of months they are gone and replaced by someone new and we have to start all over again. (Software developer, Cindicom)

Working together in teams and trying to solve software development problems together and deliver successful projects necessitated some continuity in the cooperation:

People are replaced, also at a relatively top level. In India you may have very good activities where you have identified things that don't work and you have people in Sweden and India who try to solve it, and then [sighs] the person [in India] is replaced. Well, you have to start again almost from scratch. This [new] person does not know the history, and does not know what we have done. He or she has to be trained. And then comes another new person and another. There are things that can take years. (Mid-level manager, Cindicom)

The teams onsite which had the longest experience of offshoring had, however, noticed that the attrition rate had decreased lately and they ascribed the decline to them having managed to organize work in a way that set up successful communication and created trusting relationships with their Indian colleagues. One example of this was the placement of meetings during Indian office hours. This interpretation receives some support from previous research that shows that the loyalty of the Indian employees diminished when British managers implemented a highly bureaucratic and rigid organizational structure to control and discipline Indian software programmers when outsourcing IT services to India (Nicholson and Sahay 2001).

\section{Operational dimensions}

One of the major changes due to offshoring experienced by our informants was related to the need to develop new processes and methodologies for knowledge transfer. One 
strategy to do this involved increased documentation. The two companies in our study used documentation strategically in the offshoring process for a dual purpose: to package the work tasks in a form making them possible to offshore and to reduce company dependency on individual employees. When asked whether the company had standardized and documented more as a result of offshoring, one of the interviewed managers responded:

I think it is an advantage to do that. [...] We want to get away from dependency on individuals; we want to be dependent on processes. That is why it is extremely important. Then if an employee quits or wants to do something else it is easy to take someone else in to start working. People have worked for us for many, many years, and everything is in their heads. (Mid-level manager, Doniman)

This quote echoes the first principle of Taylor's scientific management theory concerning the need to render the labor process independent of the individual employee's knowledge (cf. Braverman 1998 [1974], p. 77 ff). In the case of software offshoring, the documentation corresponds to the gathering of knowledge, and makes the corporation independent of individual software developers. Some teams therefore put a lot of energy and effort into documentation. Documentation was also associated with problems such as inefficiency, work intensification, and deskilling, however. The employees found it timeconsuming to document knowledge in order to transfer it to another cultural context, and it removed the focus from what they perceived as their core tasks, for which they could use their expert knowledge as software developers. One of the software developers described how his work had changed due to offshoring:

For me, it means that I have to spend a lot of time on documentation. I have to be very specific in my instructions to this Indian consultant. [...] My time is used for stuff that I don't really want to do. I do not think it is fun. My job is becoming more boring and I am producing less. (Software developer, Doniman)

Some researchers question whether all knowledge is migratory, and claim that certain kinds of knowledge are embedded in context and therefore cannot be codified and split into smaller modules in order to be transferred to a new context (Grote and Täube 2006; Nicholson and Sahay 2004). Unless this tacit knowledge is managed and made explicit, offshoring is a risky project. Some of the teams in our study managed to transfer tacit knowledge as well, although not primarily through increased documentation. Instead of documenting knowledge in order to transfer this to India, they used a strategy that involved expanding the teams to also include their Indian colleagues. These dual-country teams worked in close cooperation, communicating intensely on a daily basis. In these teams, documentation and standardization of work did not seem to have been a major issue. The knowledge transfer was handled by an ongoing face-to-face, or, more often, voice-to-voice, interaction. This strategy could minimize the need for documentation in the knowledge transfer activities. Compared to the content of work before offshoring, these teams became involved in more meetings and had more administrative tasks. Where they previously solved problems in very informal ways and took decisions while passing each other's desks, they were instead now arranging regular, well-structured transnational meetings. Not surprisingly, this strategy was expressed 
most strongly by employees and managers in Cindicom-the company that used captive offshoring. One of the Swedish software developers explained why his team chose to establish close cooperation instead of documenting the work tasks and the advantages with this strategy:

We have been doing this in this small team for about 20 years. And sure, much of it is not specified. And now when we have to have them there [in India], then we chose to work with them very closely and to have them with us every day, as you saw at the meeting, because that's the most efficient way. Otherwise, if you are not going to discuss with them, you would need to write down these specifications in detail and it would take more time than if you did it yourself, to exaggerate it a bit. (Software developer, Cindicom)

The strategy this team used could also be interpreted in relation to the fact that all team members onsite took a lot of pride in their work and in what they had accomplished together over the years. The option to have an Indian team just writing code was something they dismissed at an early stage, when they first learnt that they would be taking part in offshoring. Highly relevant in this context is that this team was given guarantees that no one would be laid off or displaced, that offshoring actually meant that the team would be expanded, and that the project would be given more resources. This team was one of the first teams in this company to be involved in offshoring, and it may not be too far-fetched to think that they were chosen and given promises that the team would be kept stable, because the management wanted to set a good example. These team members resisted the idea of documentation based on arguments about efficiency but also on arguments about not contributing to deskilling of their Indian colleagues: 'Everyone is just as important in our team knowledge-wise, and everyone contributes. It's our team in India that has the technical competence' (Mid-level manager, Cindicom).

This is a strategy that can, therefore, also be interpreted as reflecting ideas about 'heterarchy' a type of networked organizational model and an antithesis to hierarchy. Gannon et al. (2014, p. 355) describe that the heterarchical organization has 'many centers' where all parts are considered 'equally capable of contributing strategic thinking and value,' also subsidiaries. It is thus an organizational model that: 'seeks to exploit competitive advantage from any part of the global organization and not just from the "home" market' (Gannon et al. 2014, p. 355).

Our interviews displayed a great variety of strategies used in the two companies, and in different teams within the same company. In other teams at Cindicom the employees identified the offshoring of routine tasks as a problem because it meant that the Indian colleagues did not contribute to problem solving or the development of new ideas: 'We can't discuss with them. We give them a finished product: "fix this!" They can't produce anything new' (Software developer, Cindicom).

Doniman also adopted a strategy in some teams designed to minimize documentation. Their strategy involved having the Indian consultants visiting the Swedish work site for longer periods of time in the initial stages of the offshoring process with the intention of training them onsite. One of the mid-level managers explained why this method was used as a successful strategy: 'We want them to sit here, close to us, because then you can have a discussion face-to-face, instead of having to document everything. It's easier to communicate if you sit in front of each other' (Mid-level manager, Doniman). Documentation, dual-country teams, and onsite visits were thus three examples of strategies 
used to overcome large geographical distances between people who need to collaborate closely in work teams.

\title{
Cultural dimensions
}

Although many of the informants appreciated the strategies for knowledge transfer that involved onsite visits or collaborating closely in cross-cultural, geographically dispersed teams, there were also frequent reports of problems with communicating with their offshore colleagues that they did not experience with onshore colleagues:

If we compare Indian and Swedish consultants, there are some things I don't need to say to a Swede at all. Here, I have to think of every detail if I talk to an Indian consultant. 'I want you to report to me, I want you to come with ideas and suggestions.' One has to be excessive in everything; I can find it a hassle. (Software developer, Doniman)

Likewise in Cindicom, the employees were critical of the time-consuming knowledge transfer process and the barriers to building up tacit knowledge over what was understood as cultural and geographical distances. Several of the onsite interviewees confirmed the need to be very detailed when communicating with Indians and many of them had learned by previous mistakes not to take a mutual understanding for granted, even when their Indian colleagues said they knew what they were expected to do. A Swedish software developer, who was no longer working with the offshore team, told us how she had experienced collaborating with the Indian colleagues:

\begin{abstract}
All the time came questions, questions, questions, questions. And I felt that they should have learnt, should be able to manage a lot themselves. The same questions can come over and over again. Once I sat speaking for several hours; informing and explaining. We really agreed that this was the way to do it. And then, after three days, comes the same question again from the same person. I asked: 'Didn't we agree some days ago?' 'Yes.' 'Well, that's the way it should be done.' 'OK.' It became so annoying that I couldn't handle it. (Software developer, Cindicom)
\end{abstract}

These experiences could be interpreted as a result of cross-cultural communication problems. Rather than being an expression of the Indian colleague not having 'learnt' how a work task should be performed, the need for verification could be an illustration of asymmetrical power relations. While the Swedish employee considered it self-evident that everybody in the team would take responsibility for getting the task done in an independent manner, the Indian colleague understood it as just as necessary to consult the Swedish colleague, who was perceived as in a superior position in the organizational hierarchy and the one who gave the order. This interpretation is in line with previous research that has described Indian organizational values as characterized by hierarchical structures, bureaucratic mentality, and patriarchal management-employee relationships (Upadhya 2009), significantly different from how work is organized in the Swedish team structure.

When work is being reorganized into offshoring, the language question can become a major concern, as reported in previous research (Cohen and El-Sawad 2007). Language 
issues can also be expected to present an even greater challenge in Swedish/Indian offshoring relations than in English/Indian offshoring relations due to the added dimension of Swedes who feel that their English may not be good enough. At the first stage of the cooperation with India, many employees in Sweden found it difficult to understand the Indian pronunciation of English. More or less all of our interviewees in both companies mentioned language issues as problematic. There was even an example narrated by our informants of an Indian employee recruited for a project having to be exchanged as noone onsite could understand what was said. In the main, onsite staff soon seemed to get used to the 'Indian way' of speaking English and language ceased to be a problem. For some it remained a problem, but a less serious one, that could be handled. For others, however, the difficulties became lasting; they said that they never got used to the Indian accent. Among the interviewees there were those who refused altogether to work with offshoring as they did not understand what their Indian colleagues were saying:

No, in principle I don't understand anything of what they say, so we have to use email instead. Basically you don't understand that they are talking English. It is really incomprehensible to me and I know English well, but I could not get used to the dialect. (Software developer, Cindicom)

The language issues thus influenced the strategies for knowledge transfer between Sweden and India. In order to avoid the problems with the accent, some teams chose to communicate only in writing and never talked with their Indian counterparts. Many teams communicated via chats or e-mails rather than phone calls or, for example, Skype meetings. One of the onsite employees explained that they never talked with their Indian colleagues but always communicated in writing: 'It works much easier. They talk very fast and it can be difficult to understand their... some speak better than others. It can be difficult to follow but they write very well' (Software developer, Cindicom). If they documented their knowledge and competence, they could thus avoid close cooperation and interaction with their Indian colleagues.

The importance of speaking Swedish was also used to justify that only the Swedish onsite employees should contact customers: 'as customers most often don't want to be contacted by someone speaking English. We have customers that demand communication in Swedish' (Software developer, Cindicom). This is an argument similar to those identified in previous research (van Marrewijk 2010) that can be used in power struggles over project control and client contact between onshore and offshore offices in IT offshoring. In such power struggles cultural differences can be constructed and used as strategic resources to argue for continuous control of strategic work tasks. In this case it was the knowledge of the Swedish language that was used as a cultural resource in arguments to support the Swedish control of communication with clients.

The Swedish employees did not just describe the language issue as a problem, however. When asked what the interviewees had learned from the offshoring cooperation, a frequently recurring response was that they had developed their language skills:

I've learned to handle meetings and, most importantly, to understand their dialect. It can be difficult at the start but it's enough that you've talked to an Indian once or twice for it to be much easier to understand. In the beginning it was really difficult. I almost hung up and went home and cried [laughter]. (Software developer, Cindicom) 
This is a kind of personal experience that can be interpreted in line with previous research on how individual responses to organizational change projects depend on individual personality and, for example, dispositional inclination, personal resilience, and risk tolerance (Erwin and Garman 2010; Markov et al. 2011; Pardo de Val and Martínez Fuentes 2003). Previous international experience, age, language skills, education, and position of the employee can either close the physical distance between the countries or increase it.

\section{Economic dimensions}

At the initial stage of offshoring, when the process was first presented, there was not one team in our study that welcomed it. Most of them eventually consented to the change, as it was made clear that staying out of it was not an option. In one exceptional case, a whole team put up outright resistance, believing that it would be possible to influence the decision taken at a high management level. In teams not yet involved in offshoring there seemed to be a lot of worry. We were told that when the manager responsible for introducing offshoring processes approached a team, a common reaction was: 'Shit, are you here? Now we're done for!'

In most teams we found workers accepting, as well as opposing, the offshoring process. The open resistance often took a business approach, involving critiques of management offshoring decisions or failed management communications. Several of our informants questioned the idea that offshoring really was a way of saving money, contrary to the perceived motivations of management. Some of the employees' critical remarks referred to the problems with offshoring accounted for above in this article. Others emphasized the special value Swedish employees contributed, compared to Indian employees:

I don't understand why they have to bring in Indian consultants when you can find the same competence in Sweden. You can even find better competence here, but they are a little cheaper [in India]. In many cases it would work out much better with Swedish consultants that you can communicate better with. That's my opinion. (Software developer, Doniman)

Although not that pronounced, our interviews also contained expressions of loss of trust between employees and management (cf. Boes and Kämpf 2010). A software developer at Doniman explained that he did not share the managers' perception of the company's success with offshoring:

The managers don't speak the whole truth. They don't mention anything negative but paint a very positive picture. That's the message they send out in all meetings. That everything has gone so well although there were some apprehensions at the start. But now it's such a success. But that's strange because that's not the feeling we have. (Software developer, Doniman)

One of the interviewees explained: 'This Fall 400 people had to leave [the company]. On two occasions. In the first round they sent jobs to India and in the second round they had offers to people who wanted to leave' (Software developer, Cindicom). When 
asked whether he felt there was a risk that his work tasks would be offshored, the interviewee replied: 'Yes, possibly. It depends on the customers in Sweden. As long as some of our customers don't want deliveries from India they need us. But if more and more customers change to deliveries from India there is a risk. That's the reality you live with in consultant companies' (Software developer, Cindicom). The employees thus also constructed a competitive situation between Sweden and India and the situation was experienced as threatening since the Indian employees were considered as highly competent.

Several interviewees worried about job losses, if not always for themselves, then for colleagues. A mid-level manager expressed his concerns:

We realize that our colleagues in India are very competent. So of course it's a little bit like this: yes, do they need us in Sweden? We're much more expensive? [...] If we are to set up a new resource, well, do we do it in Sweden, or do we do it in India? Yes, but why not do it in India, it costs only a third. [...] Certainly, I can understand those who are a bit worried. (Mid-level manager, Cindicom)

At Cindicom also the employees described insecurity and lay-offs:

There have been a lot of cutdowns in our company. In the last 4-5 years. We've lost many colleagues in our group. The workload is hard. They've said that they'll try to offshore as much as possible. But the attrition rate is high in India so they chose to keep it here then. So, it's pretty... it's tough. (Software developer, Cindicom)

Some of the informants also problematized offshoring not so much from their company perspective but from a perspective that involved not contributing to increased unemployment in Swedish society. They were thus critical that the offshoring decision was based on short-term business values rather than long-term societal values:

I think it's a disaster. I think it's wrong. Because it means that we don't consider the employees in our company. We have high unemployment and from a societal perspective it would be better to employ people in our close proximity. Maybe the company saves some money but society loses in the long run. (Mid-level manager, Doniman)

As seen above, some of the mid-level managers were critical of the decision to offshore, just like the employees, but like economists (cf. Blinder 2006), most managers interviewed said they saw offshoring as an economic necessity, and believed it was unavoidable. They discussed the offshoring in their company in neutral and not value-laden terms. This does not, however, mean that they were happy about it. The increased pressure on cost efficiency underlies the following declaration as to the current situation:

We are in business; it's not a social activity. [...] We don't do this as charity; we do this for the company to make money. That's the way it is. There are profit demands on everything we do. That's how it is. And the assignment is to do it in the best possible way at the lowest possible cost, I guess. (Mid-level manager, Cindicom) 
When asked what they thought of offshoring as a phenomenon, many of them began their response by sighing deeply and then expressing their worries about the future of the Swedish IT industry:

[Sighs] It is quite a natural part of our development and globalization. Of course, you feel uneasy, because when you do business or whatever, you feel the threat from Asia. They're pretty fast-footed. They have good skills, they are numerous, they have good prices. [...] It is obvious that if this trend continues, either we have to meet them with costs somehow, or it will be more and more offshore. And then it will be fewer jobs in Sweden. This is the way it is, we are in a way impoverishing ourselves. (Mid-level manager, Cindicom)

Another onshore manager declared very frankly that, by offshoring, the company was training and creating its own future competitors:

That's the problem with offshoring. We can lose knowledge that disappears from Sweden. Some companies transfer all the knowledge and then they quite often start their own firm and start competing for clients because they possess the whole solution. While other companies don't share all the knowledge, in order not to create a competitor, so to speak. (Mid-level manager, Cindicom)

\section{Concluding discussion}

Our analysis highlights the fact that working conditions for highly qualified IT experts have been significantly redesigned in several different ways as a result of offshoring, most obviously due to the need for knowledge transfer between the onshore and the offshore working sites. These changes are related to the introduction of several new aspects: a new division of labor, new work tasks, new team members, new communication skills requirements, new language skills requirements, and new external threats. In this section we will discuss how onshore employees' experiences of IT offshoring to India related to power relations within the onshore firms and between the firms onshore and offshore.

\section{Power relations within firms}

We argue that Taylor's three management principles are useful in order to understand the effects of offshoring on the labor process onshore. These principles are most obviously reflected in the strategies regarding knowledge transfer and the decision to use the strategy of documenting the software developers' work and competence. Whereas the employees were previously the sole owners of knowledge of the work process, it was now put on paper (or more correctly in these cases: 'on the screen') and disseminated across the globe. Offshoring thus contributed to a separation of conception from execution in new ways and to an increased extent in the onsite companies. Previous research has suggested that the result is that the companies that offshore become less dependent on their onsite developers, as they become more replaceable. When development tasks can be brought over to India, the bargaining power of onsite staff in specialist careers is compromised. This can be understood as an effect of a reserve army of labor (Boes 
and Kämpf 2010; Huws 2006, 2010a, 2010b). Thus, it is suggested that offshoring changes the power relations between employers and employees, putting 'pressure on the core work force to make concessions regarding their employment conditions' (Huws et al. 2009, p. 78). The tasks sent to India needed to be replaced by new ones onsite, unless onsite workers are dismissed or relocated. This seems to constitute compelling reasons for Swedish onsite employees to resist documentation of their knowledge as that would render them substitutable and weaken their professional position in the company.

In our case study firms, however, instead of centralizing all planning of work, all conception, and all control and monopoly to management level, this was focused to the employees onsite. The major change in the labor process for onsite employees was instead the reduction of technical, executive work tasks and the increase of strategic, management tasks. Nevertheless, this was also met with resistance as some of the employees missed the technical work that was being offshored and not all of them appreciated the new managerial tasks. They also verbalized resistance toward the temporary deskilling during the documentation phase. Resistance to organizational changes such as offshoring can take many forms. The most obvious way for onshore employees to resist offshoring would be to obstruct the knowledge transfer process (Meil 2012). Our interviews did not provide explicit evidence of this, although that does not mean that it did not occur. As previous research has shown, there are other, more implicit ways of resisting offshoring. An unwillingness to understand what the Indian colleagues are saying is another way to impede the offshoring process.

When talking about previous working conditions, some of the software developers who had a long working history showed clearly with smiling faces how much they had enjoyed the days and the working conditions of the past. The worsening of working conditions cannot be attributed solely to offshoring, however. Rather, offshoring has accentuated an already ongoing process and introduced new changes in working conditions. This is a fairly new situation. Although the dotcom crisis showed that there is a conflict of interest between employees and managers in the IT sector, this has now been accentuated by offshoring.

Whereas economists predict the effects of offshoring mostly on a national or a global level, and sometimes on a company level, it is individual employees who will bear the brunt of the harsh adjustment costs that arise from losing their jobs, by having to reorient themselves in the labor market and by needing to retrain for new jobs. Although safety nets are (still) comparatively strong in Sweden, many of our interviewees expressed worries about what offshoring will mean for them. The foremost worry is, of course, the loss of jobs. Staff onsite, as well as local unions, had asked management to show economic calculations of how much was spent and how much was saved by offshoring, but they said they did not receive any answers. The financial aspects of offshoring thus seemed to be secrets well-kept at a high managerial level, which was a discretion that reinforced resistance.

Although some onsite staff managed to identify positive aspects as well, everybody would prefer offshoring not to happen. It was evident that there were two sides to offshoring when it came to individual employees' reactions. On the bright side, we found the ones enjoying getting to know a new culture, finding friends on the other side of the globe, and improving their English. On the less bright side, there were the ones who felt threatened by what was happening and who tried to resist the process. On the whole, although there were important exceptions, it was employees with medium or low IT 
education who were most worried. It was among these that we found most resistance and also the most frequent expressions of racial prejudice. None of the highly educated developers expressed racial prejudice. To a large extent, then, it seems the educational level and the position in the labor market that it lends are important factors for how individual workers respond to the new situation presented by offshoring, since these factors determine to what extent the employment position becomes threatened by offshoring.

\section{Power relations between firms}

The study includes two companies that use two different kinds of business models for offshoring: the offshore outsourcing model with services supplied by an external supplier located in another country, and the internal offshoring model, also known as captive offshoring, in which a company uses its own offshore software development center to supply its internal demand (Prikladnicki and Audy 2012). Existing literature on offshoring usually does not differentiate or compare these two different business models for offshoring, but our results show the need to investigate both models further, and in tandem. A captive offshoring strategy seems to support greater sharing of knowledge between onshore and offshore employees and also reduces some of the negative experiences of offshoring shared by the onsite employees. Captive offshoring thus facilitates the building of cross-national teams and efficient collaborations between onshore and offshore teams.

The analysis highlights the amount of interaction needed for clarifications, feedback, and discussions between sites, which indicates that the offshored work tasks were still complex, in spite of routinization and documentation. If the onsite team used a strategy that did not involve a lot of documentation, they needed to have more meetings and do more administrative tasks in order to transfer knowledge. Previous research has emphasized how important face-to-face meetings are for relationship building, in order to connect and create trust and respect (Strengers 2014). Without such face-toface meetings it can be difficult to pick up all the necessary sensory cues normally used to interpret directions, orders, or suggestions from co-workers or superiors. The absence of the physical body can also be associated with disrespect and a lack of regard for staff welfare and well-being, something previous research has implied could be particularly important in Asia (Strengers 2014).

The challenges experienced by onsite employees were also related to the temporary character of the team composition due to high attrition rate in India. The high attrition rate in India is a recurring theme in most reports on problems with offshoring software development to India (Sahay et al. 2007; Upadhya 2009). Although turnover is not actually higher in the IT industry as compared with many other industries in India, attrition and retention of talent is a big challenge in this knowledge-intensive sector (Deloitte 2012). The problem with repeated knowledge transfer is especially evident for those teams who choose to establish a close co-operation with their Indian counterparts. A successful co-operation in these teams depends not only on formal qualifications but also on long-term relationships. These teams were therefore more vulnerable to attrition. While most previous research on Indian business relations have pointed out the high attrition rate and the challenges associated with it, our study also identifies that onsite strategies

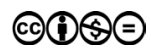


could be used in order to minimize the offshore attrition rate. Offering offshore employees a more beneficial employment situation can facilitate the creation of trust, loyalty, and commitment and induce them to stay to a higher degree.

Our study also contributes to existing research on global offshoring by emphasizing some themes that are specific to the Swedish/Indian offshoring relationship. One such theme concerns language issues. While many Swedes find it embarrassing not to be skilled in English, it is something they do not like to admit. It is also possible that the Swedish employees, due to their own lack of language skills, make the Indians responsible for the communication problems. The Indians are said to speak in an incomprehensible manner. There is reason to believe that the problems with language on the Swedish side are greater than management are aware of. The fact that very similar situations have been reported in UK-India offshoring relationships (cf. e.g., Cohen and El-Sawad 2007), however, would suggest that it is not necessarily an onshore language problem but a defense mechanism against a perceived threat.

\section{Global power relations}

Postcolonial theory can help us understand the asymmetries of power in the relationships between vendor organizations in Asia and their Western client organizations (Ravishankar et al. 2013). It is important to avoid interpretations and analyses that replicate an elitist bias about subordination in terms of class, caste, gender, race, language, culture (Spivak 1999). The postcolonial theoretical framework is not intrinsic to this article and Sweden does not have a colonial past with India. Notwithstanding this, the results reported in this article can be placed in the context of the broader phenomenon of increased global software offshoring and could as such be discussed in the context of postcolonial power relations in the global economy, both in relation to the economic exchanges that take place between onshore and offshore and the cultural prejudices. There were, for example, tendencies to a lack of solidarity between onsite and offshore employees but we also found examples of the opposite-solidarity and team-building efforts.

The offshoring process resulted in onsite staff ending up in a superior position visà-vis their Indian colleagues. Even if some of them were trying hard to make the relationship between onsite and offsite equal, it was obvious that it was the onsite employees who enjoyed a higher status. A consequence of offshoring was thus that a new bottom level in India was added to the organizational hierarchy, creating a level below onsite personnel, who thereby passively moved up one step in the hierarchy and in the value chain. Consistent with the theory of this kind of expanded hierarchy, work contents changed for onsite staff, administrative and managerial tasks were added, and some of the development tasks were sent away to India.

If mainly jobs with lower skills requirements are offshored, there will be less demand onshore for labor with other than high skills. Studies of the situation in the USA as well as Europe provide some statistical support for this assumption, showing that the offshoring of service jobs raises relative demands for high-skilled workers (Crinò 2007). Although these results have been obtained on aggregate groups of service jobs, we do not really have reason to believe that IT jobs would deviate from the pattern. Thus, offshoring of IT jobs should principally be threatening employees with low or 
medium education in IT. This is also suggested by our data as those onsite employees that expressed most resistance toward offshoring were also the ones with the most insecure positions.

\section{Acknowledgments}

This project has been supported by the Swedish Research Council and the Swedish Research Council for Health, Working Life and Welfare. The authors are grateful for the constructive and helpful comments from two anonymous reviewers on an earlier draft.

\section{References}

Ainamo, A., et al. (2010) 'Global Projects: Strategic Perspectives.' Scandinavian Journal of Management 26(4): 343-351. doi: http://dx.doi.org/10.1016/j.scaman.2010.09.005.

Amin, A. and Cohendet, P. (2005) 'Geographies of Knowledge Formation in Firms.' Industry and Innovation 12(4): 465-486. doi: http://dx.doi.org/10.1080/13662710500381658.

Andrews, C. K., Lair, C. D. and Landry, B. (2005) 'The Labor Process in Software Startups. Production on a Virtual Assembly Line.' In R. Barrett (ed) Management, Labour Process and Software Development. Reality Bytes. Oxon and New York: Routledge.

Aneesh, A. (2001) 'Skill Saturation: Rationalization and Post-Industrial Work.' Theory and Society 30(3): 363-396. doi: http://dx.doi.org/10.1023/A:1017567412100.

Arora, A., Gambardella, A. and Torrisi, S. (2001) 'In the footsteps of the Silicon Valley? Indian and Irish software in the international division of labour.' SIEPR Discussion Paper No. 00-41. Stanford: Stanford University.

Barrett, R. (2001) 'Labouring Under an Illusion. The Labour Process of Software Development in the Australian Information Industry.' New Technology, Work and Employment 16(1): 18-34. doi: http://dx.doi.org/10.1111/1468-005X.00074.

Barrett, R. (2005) 'Introduction: Myth and Reality.' In R. Barrett (ed) Management, Labour Process and Software Development. Reality Bytes. Oxon and New York: Routledge.

Beirne, M., Ramsay, H. and Panteli, A. (1998). 'Developments in Computing Work: Control and Contradiction in the Software Labour Process'. In P. Thompson and C. Warhurst (eds), Workplaces of the Future. Basingstoke: Macmillan.

Bhalla, A., Sodhi, M. M. S. and Son, B. G. (2008) 'Is More IT Offshoring Better? An Exploratory Study of Western Companies Offshoring to South East Asia.' Journal of Operations Management 26(2): 322-335. doi: http://dx.doi.org/10.1016/j.jom.2007.02.005.

Blinder, A. S. (2006) 'Offshoring: The Next Industrial Revolution?' Foreign Affairs, March/ April 2006.

Boes, A. and Kämpf, T. (2010) 'Offshoring and the New Insecurities: Towards New Types of "White Collar Consciousness" in Germany in Globalised Working Environments.' Work Organisation, Labour \& Globalisation 4(1): 104-119.

Braverman, H. (1998 [1974]) Labor and Monopoly Capital. The Degradation of Work in the Twentieth Century. New York: Monthly Review Press.

Bruyn, T. D. and Ramioul, M. (2006) Offshore Outsourcing. A Handbook for Employee Representatives and Trade Unionists. Brussels: Making Offshore Outsourcing Sustainable (MOOS).

Carmel, E. and Tija, P. (2005) Offshoring Information Technology. Sourcing and Outsourcing to a Global Workforce. Cambridge: Cambridge University Press.

Castells, M. (1996) The Rise of the Network Society. Oxford: Blackwell. 
Cohen, L. and El-Sawad, A. (2007) 'Lived Experiences of Offshoring: An Examination of UK and Indian Financial Service Employees' Accounts of Themselves and One Another.' $\mathrm{Hu}$ man Relations 60(8): 1235-1262. doi: http://dx.doi.org/10.1177/0018726707081662.

Computer Sweden (2013a) IT-jättarna krymper i Sverige. (The IT giants are shrinking in Sweden.) http://computersweden.idg.se/2.2683/1.531126?utm source=dmdelivery\&utm medium=email\&utm content=S\%C3\% A5\%20sk \%C3\% A4r\%20j\%C3\%A4ttarna \% 20 ned $\% 20 \mathrm{i} \% 20$ Sver \&utm campaign=CS $\% 20$ Dagliga $\% 202013-10-31 \% 20$ 8\%3A54\%3A45, Accessed November 4, 2013.

Computer Sweden (2013b) Tieto-bossen: Konkurrensen från Indien har ökat radikalt. (The Tieto boss: Competition from India has increased drastically.) http://computersweden.idg.se/2.2683/1.527911?utm source=dmdelivery\&utm medium=email\&utm content=Tieto-bossen $\% 3 \mathrm{~A} \% 20$ Konkurrensen $\% 20 \mathrm{fr} \% \mathrm{C} 3 \&$ utm campaign=CS $\% 20 \mathrm{Da}-$ gliga \%202013-10-15\%209\%3A13\%3A52, Accessed November 4, 2013.

Crinò, R. (2007) Skill-Biased Effects of Service Offshoring in Western Europe. Working Paper 205. Bocconi University: CESPRI.

Deloitte. Human Capital Advisory Services (2012) Compensation Trends Survey 2012.

Dossani, R. and Kenney, M. (2007) 'The Next Wave of Globalization: Relocating Service Provision to India.' World Development 35(5): 772-791. doi: http://dx.doi.org/10.1016/j. worlddev.2006.09.014.

Dou, Y. and Sarkis, J. (2010) 'A Joint Location and Outsourcing Sustainability Analysis for a Strategic Offshoring Decision.' International Journal of Production Research 48(2): 567-592. doi: http://dx.doi.org/10.1080/00207540903175145.

Ekholm, K. and Hakkala, K (2005) The Effect of Offshoring on Labor Demand: Evidence from Sweden. Working Paper No. 654, 2005. Stockholm: The Research Institute of Industrial Economics.

Erwin, D. G. and Garman, A. N. (2010) 'Resistance to Organizational Change: Linking Research and Practice.' Leadership and Organization Development Journal 31(1): 39-56. doi: http://dx.doi.org/10.1108/01437731011010371.

Fereday, J. and Muir-Cochrane, E. (2006) 'Demonstrating Rigor Using Thematic Analysis: A Hybrid Approach of Inductive and Deductive Coding and Theme Development.' International Journal of Qualitative Methods 5(1): 1-11.

Florida, R. L. (2002) The Rise of the Creative Class and How It's Transforming Work, Leisure, Community and Everyday Life. New York: Basic Books.

Ford, J. D., Ford, L. W. and D'Amelio, A. (2008) 'Resistance to Change: The Rest of the Story.' Academic Management Review 33(2): 362-377. doi: http://dx.doi.org/10.5465/ AMR.2008.31193235.

Friedman, T. L. (2005) The World Is Flat. A Brief History of the Globalized World in the $21^{\text {st }}$ Century. London: Allen Lane.

Gannon, B., Wilson, D. and Powell, P. (2014) 'Investigating the Information Systems Heterarchy.' Information Systems Management 31(4): 353-364. doi: http://dx.doi.org/10.108 $0 / 10580530.2014 .958345$.

Grote, M. H. and Täube, F. A. (2006) 'Offshoring the Financial Services Industry: Implications for the Evolution of Indian IT Clusters.' Environment and Planning A 38: 1287-1305. doi: http://dx.doi.org/10.1068/a37256.

Hovlin, K. (2006) Offshoring IT Services. A Swedish Perspective. Östersund: Swedish Institute for Growth Policy Studies.

Huws, U. (2006) 'What Will We Do? The Destruction of Occupational Identities in the Knowledge-Based Economy.' Monthly Review 57(8): 1-8. doi: http://dx.doi.org/10.14452/MR057-08-2006-01 2 .

Huws, U. (2010a) 'Bridges and Barriers: Globalization and the Mobility of Work and Workers.' Work Organisation, Labour and Globalisation 6(1): 1-7. 
Huws, U. (2010b) 'New Forms of Work; New Occupational Identities.' In N. Pupo and M. Thomas (eds) Interrogating the 'New Economy': Restructuring Work in the $21^{\text {st }}$ Century. Peterborough, Ontario: Broadview Press.

Huws, U., Dahlmann, S., Flecker, J., Holtgrewe, U., Schönauer, A., Ramioul, M. and Geurts, K. (2009) Value Chain Restructuring in Europe in a Global Economy. Leuven: HIVA.

Ilavarasan, P. V. (2008) 'Software Work in India. A Labour Process View.' In C. Upadhya and A. R. Vasavi (eds) In an Outpost of the Global Economy. Work and Workers in India's Information Technology Industry. London: Routledge.

Kenney, M., Massini, S. and Murtha, T. P. (2009) 'Offshoring Administrative and Technical Work: New Fields for Understanding the Global Enterprise.' Journal of International Business Studies 40(6): 887-900. doi: http://dx.doi.org/10.1057/jibs.2009.22.

King, R. W. (2005) 'Innovation in Responding to the "Threat” of IT Offshoring.' Information Systems Management 22(4): 80-81. doi: http://dx.doi.org/10.1201/1078.10580530/455 20.22.4.20050901/90032.8.

King, R. W. (2008) 'Issues in IS Offshoring.' Information Systems Management 25(3): 287289. doi: http://dx.doi.org/10.1080/10580530802151244.

Lacity, M. C., Khan, S. A. and Willcocks, L. P. (2009) 'A Review of the IT Outsourcing Literature: Insights for Practice.' Journal of Strategic Information Systems 18(3): 130-146. doi: http://dx.doi.org/10.1016/j.jsis.2009.06.002.

Lewin, A. Y., Massini, S. and Peeters, C. (2009) 'Why Are Companies Offshoring Innovation? The Emerging Global Race for Talent.' Journal of International Business Studies 40(6): 901-925. doi: http://dx.doi.org/10.1057/jibs.2008.92.

Luftman, J. and Kempaiah, R. M. (2007) 'The IS Organization of the Future: The IT Talent Challenge.' Information Systems Management 24(2): 129-138. doi: http://dx.doi. org/10.1080/10580530701221023.

Marklund, G. (2007) Globaliseringen och konkurrensen om kunskapsintensiva jobb. Underlagsrapport nr 2 till Globaliseringsrådet. (The Globalization and Competition for Knowledge-Intensive Jobs.) Stockholm: Regeringskansliet, Utrikesdepartementet, Globaliseringsrådet.

Markov, R., Wiener, M. and Amberg, M. (2011) 'Distance Advantages in IS Nearshoring: Do They Matter?' Proceedings of the Seventeenth Americas Conference on Information Systems, Detroit, Michigan, August 4-7, 2011.

van Marrewijk, A. (2010) 'Situational Construction of Dutch-Indian Cultural Differences in Global IT Projects.' Scandinavian Journal of Management 26(4): 368-380. doi: http:// dx.doi.org/10.1016/j.scaman.2010.09.004.

Massini, S., Perm-Ajchariyawong, N. and Lewin, A. Y. (2010) 'Role of Corporate-Wide Offshoring Strategy on Offshoring Drivers, Risks and Performance.' Industry and Innovation 17(4): 337-371. doi: http://dx.doi.org/10.1080/13662716.2010.496242.

Mattila, L. and Strandell, A.-C. (2006) Att definiera och mäta flytt av produktion. (To define and measure relocation of production.) A2006:005. Stockholm: ITPS.

McCabe, D. (2014) 'Making Out and Making Do: How Employees Resist and Make Organisational Change Work through Consent in a UK Bank.' New Technology, Work and Employment 29(1): 57-71. doi: http://dx.doi.org/10.1111/ntwe.12023.

Meil, P. (2012) 'Consent and Content: Effects of Value Chain Restructuring on Work and Conflict in Highly Skilled Workforces.' Work Organisation, Labour and Globalisation 6(2): 8-23.

Metters, R. and Verma, R. (2008) 'History of Offshoring Knowledge Services.' Journal of Operations Management 26: 141-147. doi: http://dx.doi.org/10.1016/j.jom.2007.02.012.

Mir, R. and Mir, A. (2009) 'From the Colony to the Corporation. Studying Knowledge Transfer across International Boundaries.' Group and Organization Management 34(1): 90113. doi: http://dx.doi.org/10.1177/1059601108329714. 
Nicholson, B. and Sahay, S. (2001) 'Some Political and Cultural Issues in the Globalisation of Software Development: Case Experience from Britain and India.' Information and Organization 11(1): 25-43. doi: http://dx.doi.org/10.1016/S0959-8022(00)00008-4.

Nicholson, B. and Sahay, S. (2004) 'Embedded Knowledge and Offshore Software Development.' Information and Organization 14(4): 329-365. doi: http://dx.doi.org/10.1016/j. infoandorg.2004.05.001.

Obama, B. (2012) State of the Union Address. Transcript: http://www.whitehouse.gov/thepress-office/2012/01/24/remarks-president-state-union-address.

Pardo de Val, M. and Martínez Fuentes, C. (2003) 'Resistance to Change: A Literature Review and Empirical Study.' Management Decision 41(2): 148-155. doi: http://dx.doi. org/10.1108/00251740310457597.

Pieterse, J. H., Caniëls, M. C. J. and Homan, T. (2012) 'Professional Discourses and Resistance to Change.' Journal of Organizational Change Management 25(6): 798-818. doi: http://dx.doi.org/10.1108/09534811211280573.

Prikladnicki, R. and Audy, J. L. N. (2012) 'Managing Global Software Engineering: A Comparative Analysis of Offshore Outsourcing and the Internal Offshoring of Software Development.' Information Systems Management 29(3): 216-232. doi: http://dx.doi.org/10 $.1080 / 10580530.2012 .687313$.

Radhakrishnan, S. (2007) 'Rethinking Knowledge for Development: Transnational Knowledge Professionals and the "New" India.' Theory and Society 36(2): 141-159. doi: http:// dx.doi.org/10.1007/s11186-007-9024-2.

Ramarapu,N.,Parzinger,M.J.andLado,A.A.(1997)'Issues in Foreign Outsourcing.' Information Systems Management 14(2): 27-31. doi: http://dx.doi.org/10.1080/10580539708907042.

Rau, M. T. (2004) 'Key Issues for Global IT Sourcing: Country and Individual Factors.' Information Systems Management 21(3): 16-21. doi: http://dx.doi.org/10.1201/1078/444 32.21.3.20040601/82472.3.

Ravishankar, M. N., Pan, S. L. and Myers, M. D. (2013) 'Information Technology Offshoring in India: A Postcolonial Perspective.' European Journal of Information Systems 22: 387-402. doi: http://dx.doi.org/10.1057/ejis.2012.32.

Rognes, J. (2008). Ett kunskapsperspektiv på outsourcing [Elektronisk resurs]. (A knowledge perspective on outsourcing.) Working Paper Series in Business Administration No 2008:5. Stockholm: SSE/EFI.

Roza, M., Van den Bosch, F. A. J. and Volberda, H. W. (2011) 'Offshoring Strategy: Motives, Functions, Locations, and Governance Modes of Small, Medium-Sized and Large Firms.' International Business Review 20: 314-323. doi: http://dx.doi.org/10.1016/j. ibusrev.2011.02.002.

Ryan, G. W. and Bernard, R. H. (2003) 'Techniques to Identify Themes.' Field Methods 15(1): 85-109. doi: http://dx.doi.org/10.1177/1525822X02239569.

Sahay, S., Nicholson, B. and Krishna, S. (2007) Global IT Outsourcing. Software Development across Borders. Cambridge: Cambridge University Press.

Simhan, T. R. (2014) 'Attrition on the rise in IT firms.' thehindubusinessline.com/features/ smartbuy/attrition-on-the-rise-in-it-firms/article5730053, Accessed June 30, 2015.

Spivak, G. C. (1999) A Critique of Postcolonial Reason. Cambridge, MA: Harvard University Press.

Srivastava, M. (2009) 'India: Worries Grow about Obama Outsourcing Policies.' Businessweek, March 3, 2009.

Statistics Sweden (2014) 'Employees 16-64 Years at National Level by Occupation (SSYK4), Sector and Sex. Year 2005-2012.' Statistical Database.

St. John, J., Guynes, C. S. and Vedder, R. (2014) 'The Client-Vendor Offshore Relationship: Success Factors.' Information Systems Management 31(2): 120-125. doi: http://dx.doi. org/10.1080/10580530.2014.890429. 
Strengers, Y. (2014) 'Meeting in the Global Workplace: Air Travel, Telepresence and the Body.' Mobilities, published online ahead of print, 1-9. doi: http://dx.doi.org/10.1080/1 7450101.2014 .902655$.

Tambe, P. B. and Hitt, L. M. (2010) 'How Offshoring Affects IT Workers.' Communications of the ACM 53(10): 62-70. doi: http://dx.doi.org/10.1145/1831407.1831426.

Tessler, S., Barr, A. and Hanna, N. (2003) 'National Software Industry Development: Considerations for Government Planners.' The Electronic Journal of Information Systems in Developing Countries 13(10): 1-17.

Thomas, R., Sargent, L. D. and Hardy, C. (2011) 'Managing Organizational Change: Negotiating Meaning and Power-Resistance Relations.' Organizational Science 22(1): 22-41. doi: http://dx.doi.org/10.1287/orsc.1090.0520.

Unionen (2008) Outsourcing \& offshoring-en facklig checklista. (Outsourcing \& offshoring-a trade union checklist.) Stockholm: Unionen.

United Nations (2012) Information Economy Report 2012. The Software Industry and Developing Countries. New York and Geneva: UN.

Upadhya, C. (2009) 'Controlling Offshore Knowledge Workers: Power and Agency in India's Software Outsourcing Industry.' New Technology, Work and Employment 24(1): 2-18. doi: http://dx.doi.org/10.1111/j.1468-005X.2008.00215.x.

Upadhya, C. and Vasavi, A.R (eds) (2008) In an Outpost of the Global Economy. Work and Workers in India's Information Technology Industry. London: Routledge.

Vaara, E. and Tienari, J. (2011) 'On the Narrative Construction of Multinational Corporations: An Antenarrative Analysis of Legimitation and Resistance in a Cross-Border Merger.' Organization Science 22(2): 370-390. doi: http://dx.doi.org/10.1287/orsc.1100.0593.

Vosselman, E. G. J. and van der Meer-Kooistra, J. (2006) 'Changing the Boundaries of the Firm: Adopting and Designing Efficient Management Control Structures.' Journal of Organizational Change Management 19(3): 318-334. doi: http://dx.doi.org/10.1108/09534810610668337.

Werner, W. (2009) 'Service Offshoring: Is Europe Different?’ Intereconomics 44(2): 96-104. doi: http://dx.doi.org/10.1007/s10272-009-0283-1.

Westermark, K. (2013) Proximity and Learning in Internationalisation: Small Swedish IT firms in India. Stockholm: Acta Universitatis Stockholmiensis.

Woodard, M. S. and Sherman, K. E. (2015) 'Toward a More Complete Understanding of Offshoring: Bringing Employees into the Conversation.' The International Journal of Human Resource Management 26(16): 2019-2038. doi: http://dx.doi.org/10.1080/095851 92.2014.971845. 